\title{
REVIEW
}

\section{Predictors and rates of treatment-resistant tumor growth in acromegaly}

\author{
G M Besser, P Burman ${ }^{1}$ and A F Daly ${ }^{2}$ \\ Department of Endocrinology, St Bartholomew's Hospital, London EC1A 7BE, UK, ${ }^{1}$ Department of Medical Sciences, University Hospital, Uppsala, \\ Sweden and ${ }^{2}$ Department of Endocrinology, CHU de Liège, Domaine Universitaire Sart-Tilman, 4000 Liege, Belgium
}

(Correspondence should be addressed to G M Besser; Email: endo@thelondonclinic.co.uk)

\begin{abstract}
Background: Multimodal therapy for acromegaly affords adequate disease control for many patients; however, there remains a subset of individuals that exhibit treatment-resistant disease. The issue of treatment-resistant pituitary tumor growth remains relatively under-explored.

Methods: We assessed the literature for relevant data regarding the surgical, medical and radiotherapeutic treatment of acromegaly in order to identify the factors that were predictive of aggressive or treatment-resistant pituitary tumor behavior in acromegaly and undertook an assessment of the rates of failure to control tumor progression with available treatment modalities.

Results: Young age at diagnosis, large tumor size, high growth hormone secretion and certain histological markers are predictors of future aggressive tumor behavior in acromegaly. Significant tumor regrowth occurs in less than $10 \%$ of cases thought to be cured surgically, whereas failure to control tumor growth is seen in less than $1 \%$ of patients receiving radiotherapy. Somatostatin analogs induce a variable degree of tumor shrinkage in acromegaly but up to $2.2 \%$ of somatostatin analog-treated tumors continue to grow. Relative to other therapies, limited data are available for pegvisomant, but these indicate that persistent tumor growth occurs in $1.6-2.9 \%$ of cases followed up regularly with serial magnetic resonance imaging scans.

Conclusions: Treatment-resistant tumor progression occurs in a small minority of patients with acromegaly, regardless of treatment modality. Young patients with large tumors or those with high pre-treatment levels of growth hormone particularly warrant close monitoring for continued tumor progression during treatment for acromegaly.
\end{abstract}

European Journal of Endocrinology 153 187-193

\section{Introduction}

Five separate treatment modalities are currently available for acromegaly: surgery, somatostatin analogs, a growth hormone $(\mathrm{GH})$ receptor antagonist, dopamine agonists and radiotherapy. The preferred primary treatment is surgery, as complete resection of an adenoma can cure the disease in more than three-quarters of microadenomas, although this decreases to less than half of macroadenomas (1). Some elderly or debilitated patients may not be suitable for surgery and others may decline this option. In cases where surgery fails to control the condition or is not performed, medical therapy or radiotherapy is necessary, either alone or in combination. Disease control in acromegaly is probably achievable for most patients using multi-modal therapy, although formal studies in this regard are required. The characteristics of the minority of patients with treatment-resistant acromegaly and the factors that determine tumor behavior in these cases have received relatively little attention. Scant data exist concerning the natural history of pituitary tumor growth in acromegaly, as surgery and radiotherapy for acromegaly have been available for nearly 100 years and medical therapy has existed for about 30 years. Without such data it is difficult to predict exactly which tumors are likely to recur during medium- to longterm follow-up. In order to examine this issue more clearly we undertook an assessment of the literature to identify patient characteristics and structural, molecular and genetic factors that may pre-dispose to aggressive pituitary tumor behavior in acromegaly. Using this information, we assessed relevant reports of continued pituitary adenoma growth in acromegaly with surgery, medical therapy and radiotherapy.

\section{Factors associated with aggressive pituitary tumor activity}

\section{Patient characteristics.}

Age In a detailed magnetic resonance imaging (MRI) study of patients with acromegaly, Lundin et al. (2) reported that pituitary tumor volume was inversely 
related to age. Similarly, two single-center studies have reported an inverse relationship between the age of patients and the likelihood of tumor persistence following surgery. In a French series of 48 patients with acromegaly, those with persistent disease after surgery were younger than satisfactorily treated patients (3). Abosch et al. (4) also found younger age to be a predictor of disease persistence after surgery. This finding may be partially a function of lower hormonal activity in older acromegalic patients. van der Lely et al. (5) reported that older patients with acromegaly have lower circulating GH and insulin-like growth factor-I (IGF-I) levels, and GH suppression with octreotide therapy is more marked in elderly patients compared with younger individuals. Related evidence exists in patients with residual nonfunctioning pituitary adenomas post surgery, as younger patients had more rapidly growing tumor remnants and a shorter time to tumor-volume doubling (6).

\section{Tumor characteristics}

Tumor size and GH secretion In many surgical series, patients with acromegaly who harbor extensive macroadenomas or those who exhibit high preoperative circulating concentrations of GH are more likely to have persistent disease despite transsphenoidal resection (4, 7-11). Larger tumors in acromegaly have also been associated with more frequent invasiveness, younger age at diagnosis and poorer responses to therapy (12). These results are in keeping with other evidence outlined above demonstrating an inverse relationship between age and tumor volume (2).

Tumor morphology Extensive morphological studies have been performed in acromegaly using surgically resected pituitary adenoma tissue. Differences in tumor behavior have been noted based on histological staining, with hormonal secretion from tumors exhibiting sparse granular staining being less responsive to pharmacological suppression than densely granulated adenomas (13). Overall, sparsely granulated adenomas are more likely to be invasive or to exhibit suprasellar extension, and surgery is less likely to be successful in these cases. Poorer outcomes, such as earlier age at diagnosis, larger tumor size and more frequent extrasellar extension have been associated with GH-secreting adenomas which exhibit dot-like cytokeratin staining, compared with those with a perinuclear/fibrillary cytokeratin staining pattern (12). Re-operations and incomplete tumor resection were four times more frequent in patients with a dot-like cytokeratin pattern than in those with the peri-fibrillary pattern, whereas the mean interval to re-operation was 16 months in the former group compared with 57 months in the latter group (14). Immunohistochemical staining of resected pituitary tumor tissue for anti-Ki-67 monoclonal antibody (MIB-1) has been shown to correlate with dural and cavernous sinus invasiveness $(15,16)$, including in patients with acromegaly (17).

At this time, matrix metalloproteinases, indices of angiogenesis and markers of cell-cycle regulation (cyclins) do not appear to play a distinctive role in indicating aggressive/treatment-resistant tumor behavior in acromegaly as compared with other pituitary tumor types $(18-20)$.

\section{Genetic markers}

A variety of genetic mutations and signalling abnormalities have been identified from studies of GH-secreting pituitary adenoma tissues, although inherited disorders account for only a minority of pituitary adenomas (21). An activating mutation of the Gs $\alpha$ gene ( $g s p)$ is present in approximately one-quarter of cases of acromegaly and tumors from such patients may be less aggressive than those not harboring the mutation (22). Despite extensive study of other molecular and genetic markers (e.g. Growth arrest and DNA-damage-inducible protein (GADD) 45 and pituitary tumor transforming gene (PTTG)) and tumor behavior in pituitary adenomas, a strong correlation between any of these markers and tumor aggression in acromegaly has yet to be demonstrated (23-26). Patients with multiple endocrine neoplasia-1 (MEN-1) exhibit more aggressive pituitary disease in general than patients with sporadic tumors (27). Perhaps reflecting this finding, a large study of 324 patients with MEN-1 reported that all 12 patients with acromegaly had macroadenomas (28). Familial acromegaly occurs very rarely in the absence of MEN-1, but is associated with early onset of disease, and larger/extensive tumors have been reported (29) compared with sporadic acromegaly, although not invariably (30).

\section{Tumor growth and persistence rates following treatment for acromegaly}

\section{Surgery}

Transsphenoidal surgery is the treatment of choice in acromegaly, particularly for patients with microadenomas $(<10 \mathrm{~mm}$ diameter) or uncomplicated macroadenomas (1). The surgical cure rate for microadenomas is around $80 \%$ but for macroadenomas it is under $50 \%$ using strict biochemical criteria (1); success rates are more favorable when surgery is performed by an experienced pituitary surgeon (8). After surgery, acromegaly frequently persists or recurs in patients with tumors complicated by extrasellar extension or invasion of peri-sellar structures. In the largest series published to date, which included 506 patients with acromegaly who underwent primary transsphenoidal surgery, the overall remission rate was $72 \%$ in noninvasive adenomas and $21.6 \%$ in invasive tumors (7). 
The recurrence rate following apparent initial surgical remission can be up to $10 \%$ in some series $(4,9,10)$. The most important predictors of unsuccessful outcome following surgery are large tumor size, extrasellar extension/invasion (high grade) and high pretreatment circulating GH levels (11).

\section{Medical therapy}

Somatostatin analogs Long-acting somatostatin analogs have been available since the mid-1980s, and depot formulations are the most frequently chosen form of medical therapy for acromegaly. Somatostatin analogs are used as adjunctive therapy for patients with persistent disease post-operatively or in the pre-operative setting to improve physical condition and induce tumor shrinkage (31). In patients who are unable or unwilling to undergo transsphenoidal surgery, somatostatin analogs have been employed as primary therapy $(32,33)$. Long-acting somatostatin analogs are effective in reducing GH, although results vary depending on baseline $\mathrm{GH}$ levels, the presence of functioning receptors for somatostatin, and duration of treatment $(34,35)$. Two substantial systematic reviews have been performed recently to examine the effects of primary and adjunctive somatostatin analog therapy on hormonal control and tumor shrinkage in acromegaly. In the first study, Freda (36) estimated that the adjunctive use of lanreotide SR or octreotide LAR normalized serum IGF-I in 48 and $66 \%$ of cases, respectively. GH control was defined as a random or mean $\mathrm{GH}$ level of $<2.0$ or $<2.5 \mu \mathrm{g} / \mathrm{l}$, respectively, or a $\mathrm{GH}$ level of $<1.0 \mu \mathrm{g} / \mathrm{l}$ post oral glucose load. Adjunctive lanreotide SR or octreotide LAR treatment in acromegaly controlled $\mathrm{GH}$ in 49 and $56 \%$ of cases, respectively (36). Primary somatostatin analog therapy normalized IGF-I in $60 \%$ of cases and controlled $\mathrm{GH}$ in $50 \%$ of cases overall. One potential confounding issue that was raised in the review was that octreotide studies specifically excluded 'non-responders', defined as those patients who exhibited a poor GH suppression response to a test dose of octreotide at preliminary screening. Freda (36) reported that octreotide-induced tumor shrinkage was quite variable with $<20 \%$ shrinkage in tumor volume occurring in $8 \%$ of patients, $20-$ $50 \%$ shrinkage in $35 \%$ of patients and larger degrees of tumor shrinkage were uncommon (36). Considering only patients receiving primary somatostatin analog therapy, results were similar, with $48 \%$ overall having tumor regression, of whom $9 \%$ had $<20 \%$ shrinkage, $32 \%$ had $20-50 \%$ shrinkage and $7 \%$ had $>50 \%$ shrinkage. Bevan (37) recently reported an extensive review of the effects of short- and long-acting somatostatin analogs on tumor shrinkage. He noted that definitions of tumor shrinkage, washout times between therapies, dosages and radiological follow-up were not standardized across most studies in the literature. In a pooled analysis of 22 studies $(n=478)$ of subcutaneous octreotide, $45 \%$ of patients had tumor shrinkage; this rose to
$51 \%$ in those receiving primary somatostatin analog therapy, but was as low as $27 \%$ in those on adjunctive therapy. For octreotide LAR $(n=180)$, the overall tumor shrinkage response rate was $57 \%$. In patients receiving primary medical therapy the response rate was $80 \%$, and for those receiving adjunctive octreotide LAR this fell to $28 \%$. When all data from all formulations of somatostatin analogs were pooled $(n=921)$, tumor shrinkage occurred in $42 \%$ of cases overall and in 52 and $21 \%$ of cases treated with primary or adjunctive somatostatin analog therapy, respectively (37). The rates of tumor progression on somatostatin analog therapy were also assessed in these two systematic analyses, with Freda (36) reporting that tumor progression occurred in $<1 \%$ of cases. In contrast, Bevan (37) estimated that, of 921 cases included in the analysis, 20 or $2.2 \%$ - had tumor growth on somatostatin analogs (37). Failure to control pituitary adenoma growth occurred in approximately $10 \%$ in individual studies using lanreotide $(38,39)$ and octreotide $(40)$, which were not included in that analysis. Another issue that may confound accurate analysis of tumor behavior in general is the fluctuation in tumor size to the order of $10-20 \%$, which can be seen during intensive MRI follow-up in individual acromegalic patients treated with somatostatin analogs (33). The effects of somatostatin analogs on tumor size do not appear to be permanent and many groups have reported that, on withdrawal of octreotide, pituitary adenomas may reexpand to their original size $(41-44)$. The issue of time to re-expansion has not been studied systematically in patients being withdrawn from depot long-acting somatostatin analog therapy and it is unknown whether tumor re-expansion follows a similar 3-4-month time course to that of increased GH/IGF-I secretion (45). It appears that somatostatin analogs induce tumor shrinkage by decreasing adenoma cell size/activity rather than inducing apoptosis $(46,47)$.

GH receptor antagonist The $\mathrm{GH}$ receptor antagonist, pegvisomant, is the most recently developed treatment for acromegaly. Pegvisomant blocks the activation of the $\mathrm{GH}$ receptor by $\mathrm{GH}$, leading to a reduction in IGFI secretion. In patients with acromegaly who were treated with pegvisomant for up to 18 months, circulating IGF-I levels were normalized in $97 \%$ of cases (48). Tumor shrinkage is not a feature of pegvisomant therapy. It has been suggested that the marked reduction in IGF-I seen during pegvisomant therapy could remove feedback inhibition of pituitary GH secretion and induce tumor growth (49). GH levels do rise initially following pegvisomant treatment but plateau quickly; this is not accompanied by a parallel increase in overall tumor size in large studies and during longer-term follow-up (48, 50). However, in one multicenter study two cases of significant increases in adenoma size were reported (51). In both cases, patients had established aggressive tumors, had 
previously undergone failed pituitary surgery and had large residual tumors still present at entry to the study. Neither patient had received previous radiotherapy. One patient, a 26 year-old woman, received intermittent pegvisomant over a 15-month period and then underwent radiotherapy. In this case tumor size also increased during a 7-month period spent not receiving any medical therapy. The other patient was also young (34 years old) and had a large tumor at diagnosis, which was still impinging on the optic chiasm 6 months after initial surgery (51). He was only partially responsive to octreotide therapy and, despite pegvisomant therapy up to a maximum dose of $40 \mathrm{mg} /$ day, IGF-I levels remained elevated and eventually began to rise. At the time of this IGF-I escape, his tumor began to cause visual symptoms and he was treated with a combination of octreotide and pegvisomant, which controlled IGF-I and resolved visual symptoms. Withdrawal of pegvisomant led to an increase in IGFI and a second surgical intervention was undertaken successfully. Since these early studies, pegvisomant has been used in the clinical setting in more than 1300 patients and has also been the subject of other prospective clinical trials in which tumor volume was assessed by regular MRI scans. A total of 313 patients have received pegvisomant during the course of completed prospective trials with a mean treatment duration of 17 months (Pfizer, data on file). During MRI follow-up in these clinical trials, increases in tumor size have been noted in seven further cases. In four of these cases the tumor size increase consisted of reexpansion of the adenoma following withdrawal of octreotide LAR. As noted above, this phenomenon has previously been reported to occur on cessation of somatostatin analog therapy $(41-43)$. During prolonged pegvisomant treatment of up to 18 months, no further tumor growth was seen in these patients. The remaining cases constituted continued progression of tumors that were noted to be actively growing off therapy $(n=1)$ or tumors that were noted to be growing during somatostatin analog therapy $(n=2)$. None of the patients with tumor enlargement while receiving pegvisomant had undergone previous radiotherapy, which is in keeping with the high efficacy of radiotherapy in controlling tumor size. Taking all available data, this suggests that tumor progression during pegvisomant therapy occurs in approximately $2-3 \%$ of patients (5-9/313; depending on the inclusion of those with re-expansion post octreotide withdrawal) in the medium term. Further data on pegvisomant in larger populations of patients treated in the clinical setting and followed with regular MRI will be needed to assess the effects on tumor progression during longterm treatment.

Dopamine agonists Dopamine $\mathrm{D}_{2}$ receptor agonists have been used to treat acromegaly since the 1970s $(52,53)$. Their overall efficacy is, however, limited in comparison with other therapeutic modalities. In a review of early clinical studies, Jaffe and Barkan (54) reported that bromocriptine 'normalized' serum GH (levels $<5 \mu \mathrm{g} / \mathrm{l}$ ) in 20\% of patients and IGF-I in only $10 \%$ of cases. More recent studies with newer dopamine agonists, such as cabergoline, have provided better hormonal control (55), particularly in tumors that cosecrete $\mathrm{GH}$ and prolactin (56). Tumor shrinkage during dopamine agonist therapy for acromegaly varies, being up to $30 \%$ of tumors in some studies $(54,57)$; the most marked shrinkage was seen in cases of $\mathrm{GH} /$ prolactin co-secretion (56). Secondary resistance to dopamine agonist therapy in terms of hormonal secretion can occur in acromegaly (58), although continued tumor progression has not been reported.

\section{Radiotherapy}

Radiotherapy is an effective treatment for acromegaly and controls both GH/IGF-I hypersecretion and tumor growth. Adequate hormonal control is achieved very slowly $(59,60)$, which necessitates appropriate medical therapy in the interim period. As hypopituitarism is a common side effect and as concerns remain over the risk of second-tumor formation after radiotherapy, this modality is an adjunctive treatment for acromegaly that cannot be controlled by surgery or medical therapy (61). Hormonal control with modern radiotherapeutic techniques like gamma-knife 'radiosurgery' increases gradually over time but the speed of response and the effects in terms controlling tumor growth have not yet been established in sufficiently large patient populations, although some early results are encouraging (62). Individual patients with aggressive tumors in acromegaly can exhibit persistent tumor growth despite both surgery and radiotherapy (63). However, tumor expansion after radiotherapy in acromegaly is unusual and occurs in only $0.3 \%$ of cases (59).

\section{Conclusions}

Multiple forms of therapy are available to achieve control of symptoms, hormonal secretion and tumor growth in acromegaly. Despite the wealth of data generated by pharmacological and other intervention studies in acromegaly, our assessment of the literature has revealed that relatively little attention has been paid to treatment-resistant acromegaly, particularly in terms of tumor progression. Tumor recurrence after apparently complete surgical resection occurs in less than $10 \%$ of cases overall $(4,9,10)$, while radiotherapy fails to control tumor growth in less than $1 \%$ of cases (59) (Table 1). With medical therapy the data are less clear-cut, as potential confounding effects, such as pre-selection of treatment-responder subgroups, variation in disease severity, and any administered pretreatment, make interpretation imprecise. Somatostatin 
Table 1 Rates of tumor progression associated with various treatment options in acromegaly.

\begin{tabular}{lcl}
\hline Treatment & Rate of tumor progression (references) & \begin{tabular}{l} 
Observations \\
\hline Surgery
\end{tabular} \\
$\begin{array}{l}\text { Somatostatin analogs } \\
\text { GH receptor antagonist }\end{array}$ & $\begin{array}{l}\text { Rate of re-growth increased in cases with high preoperative } \\
\text { GH levels, large tumor size or evidence of tumor invasion. } \\
\text { Higher rates of tumor progression have been reported in } \\
\text { individual studies (10-17\%). }\end{array}$ \\
$\begin{array}{l}\text { Patients with tumor expansion during pegvisomant treatment } \\
\text { can be divided into those exhibiting tumor re-expansion } \\
\text { following somatostatin analog withdrawal or continued } \\
\text { growth of tumors, predominantly in young patients. }\end{array}$ \\
$\begin{array}{l}\text { Data are currently lacking on the tumor progression rate } \\
\text { seen with various dopamine agonists in acromegaly. }\end{array}$ \\
Radiotherapy is associated with a low rate of tumor progression.
\end{tabular}

analogs were shown to induce a variable degree of tumor shrinkage in 21 and $52 \%$ of patients that received adjunctive or primary therapy, respectively. These results come predominantly from studies in which patients were demonstrated to be somatostatin analog-sensitive before somatostatin analog therapy was initiated (37). Tumor progression appears to occur in up to $2.2 \%$ of patients treated with somatostatin analogs $(37,36)$, but data on these patients and their tumor characteristics are very scant. Withdrawal of somatostatin analog therapy can be associated with re-expansion of pituitary tumors to their pre-treatment levels $(2,41,42,43,44)$. Attention

Table 2 Factors that may influence tumor aggressiveness in acromegaly.

\begin{tabular}{|c|c|}
\hline Factor & Observations (references) \\
\hline Age & $\begin{array}{l}\text { Younger patients appear to have poorer } \\
\text { outcomes in acromegaly }(3,4) \text {. }\end{array}$ \\
\hline $\begin{array}{l}\text { Tumor size and } \\
\text { GH secretion }\end{array}$ & $\begin{array}{l}\text { Larger or extensive tumors and invasive } \\
\text { tumors are associated with poorer } \\
\text { responses to therapy. Patients with high } \\
\text { GH levels pre-treatment are less likely to } \\
\text { achieve adequate control compared with } \\
\text { patients with lower GH levels }(4,8-12) \text {. }\end{array}$ \\
\hline $\begin{array}{l}\text { Molecular \& genetic } \\
\text { factors }\end{array}$ & $\begin{array}{l}\text { gsp, PTTG, and GADD } 45 \text { gene mutations } \\
\text { potentially associated with tumor outcomes } \\
\text { in acromegaly }(21,22,25,26) \text {. Fibroblast } \\
\text { growth factor receptor-4 expression is } \\
\text { implicated in pituitary tumorigenesis } \\
(23,24) \text {. MEN-1-associated acromegaly } \\
\text { appears to have a higher rate of } \\
\text { macroadenomas }(28) \text {. Familial acromegaly } \\
\text { occurs in younger patients and is } \\
\text { associated with extensive pituitary } \\
\text { adenomas }(29,30) \text {. }\end{array}$ \\
\hline Tumor morphology & $\begin{array}{l}\text { Sparsely granulated adenomas have poorer } \\
\text { outcomes than densely granulated } \\
\text { adenomas (13). A dot-like cytokeratin } \\
\text { adenoma staining pattern is associated } \\
\text { with poorer outcomes than perinuclear } \\
\text { cytokeratin staining }(12,14) \text {. Higher Ki- } 67 \\
\text { labeling index may correlate with tumor } \\
\text { invasion of the cavernous sinus } \\
\text { in acromegaly. }\end{array}$ \\
\hline
\end{tabular}

has been focused on pegvisomant in terms of tumor growth, which occurred in $1.6 \%$ of patients treated in clinical trials, rising to $2.9 \%$ if cases of tumor re-expansion on cessation of somatostatin analog therapy are included. Data describing the natural history of tumor growth in acromegaly do not exist, so it is impossible to state whether these rates of failure to control tumor growth are more or less than those that would be expected due to the innate behavior of aggressive tumors. Some factors may be predictive of continued tumor progression, including young age at diagnosis, high GH levels, large or extensive tumors, familial disease and various pathological indices (Table 2). There exists a clear need to study the causes and management of treatment-resistant acromegaly, particularly in terms of tumor progression. Well-designed MRI studies in patients potentially at risk from an aggressive tumor would be very useful to verify the true rates of therapeutic failure across all treatment modalities.

\section{Acknowledgements}

G M B has received support for research and consulting from Pfizer, Sensus, Novartis, and Ipsen. P B was previously an employee of Pfizer. A F D has received support for research and consulting from Pfizer, Novartis, and Schering-Plough Corp.

\section{References}

1 Giustina A, Barkan A, Casanueva FF, Cavagnini F, Frohman L, Ho K, Veidhuis J, Wass J, von Werder K \& Melmed S. Criteria for cure of acromegaly: a consensus statement. Journal of Clinical Endocrinology and Metabolism 200085 526-529.

2 Lundin P, Eden Engstrom B, Karlsson FA \& Burman P. Long-term octreotide therapy in growth hormone-secreting pituitary adenomas: evaluation with serial MR. American Journal of Neuroradiology $199718765-772$.

3 Salaun C, Foubert L, Vialatou M, Kujas M \& Turpin G. Prognostic factors in the surgical management of acromegaly (in French). Annales Medicine Interne (Paris) 1999150 195-198. 
4 Abosch A, Tyrrell JB, Lamborn KR, Hannegan LT, Applebury CB \& Wilson CB. Transsphenoidal microsurgery for growth hormone-secreting pituitary adenomas: initial outcome and long-term results. Journal of Clinical Endocrinology and Metabolism $1998833411-3418$.

5 van der Lely AJ, Harris AG \& Lamberts SW. The sensitivity of growth hormone secretion to medical treatment in acromegalic patients: influence of age and sex. Clinical Endocrinology 1992 $37181-185$.

6 Tanaka Y, Hongo K, Tada T, Sakai K, Kakizawa Y \& Kobayashi S. Growth pattern and rate in residual nonfunctioning pituitary adenomas: correlations among tumor volume doubling time, patient age, and MIB-1 index. Journal of Neurosurgery 200398 359-365.

7 Nomikos P, Buchfelder M \& Fahlbusch R. The outcome of surgery in 668 patients with acromegaly using current criteria of biochemical 'cure'. European Journal of Endocrinology 2005152 379-387.

8 Ahmed S, Elsheikh M, Stratton IM, Page RC, Adams CB \& Wass JA. Outcome of transphenoidal surgery for acromegaly and its relationship to surgical experience. Clinical Endocrinology 1999 $50561-567$.

9 Beauregard C, Truong U, Hardy J \& Serri O. Long-term outcome and mortality after transsphenoidal adenomectomy for acromegaly. Clinical Endocrinology 200358 86-91.

10 De P, Rees DA, Davies N, John R, Neal J, Mills RG, Vafidis J, Davies JS \& Scanion MF. Transsphenoidal surgery for acromegaly in Wales: results based on stringent criteria of remission. Journal of Clinical Endocrinology and Metabolism 200388 3567-3572.

11 Kreutzer J, Vance ML, Lopes MB \& Laws ER Jr. Surgical management of GH-secreting pituitary adenomas: an outcome study using modern remission criteria. Journal of Clinical Endocrinology and Metabolism $2001864072-4077$.

12 Bando H, Sano T, Ohshima T, Zhang CY, Yamasaki R, Matsumoto K \& Saito S. Differences in pathological findings and growth hormone responses in patients with growth hormoneproducing pituitary adenoma. Endocrinology Japan 199239 355-363.

13 Ezzat S, Kontogeorgos G, Redelmeier DA, Horvath E, Harris AG \& Kovacs K. In vivo responsiveness of morphological variants of growth hormone-producing pituitary adenomas to octreotide. European Journal of Endocrinology 1995133 686-690.

14 Mazal PR, Czech T, Sedivy R, Aichholzer M, Wanschitz J, Klupp N \& Budka H. Prognostic relevance of intracytoplasmic cytokeratin pattern, hormone expression profile, and cell proliferation in pituitary adenomas of acromegalic patients. Clinical Neuropathology $200120163-171$.

15 Jaffrain-Rea ML, Di Stefano D, Minniti G, Esposito V, Bultrini A, Ferretti E, Santoro A, Scucchi LF, Gulino A \& Cantore G. A critica reappraisal of MIB-1 labelling index significance in a large series of pituitary tumours: secreting versus non-secreting adenomas. Endocrine Related Cancer 20029 103-113.

16 Kitz K, Knosp E, Koos WT \& Korn A. Proliferation in pituitary adenomas: measurement by MAb KI 67. Acta Neurochirurgica (Wien) 199153 (Suppl) 60-64.

17 Iuchi S, Saeki N, Uchino Y, Higuchi Y, Tatsuno I, Nakamura S, Yasuda T \& Yamaura A. Cavernous sinus invasion and tumor proliferative potential of growth hormone-producing pituitary tumors. Endocrine Journal 200047 (Suppl) S77-S79.

18 Turner HE, Nagy Z, Esiri MM, Harris AL \& Wass JA. Role of matrix metalloproteinase 9 in pituitary tumor behavior. Journal of Clinical Endocrinology and Metabolism 200085 2931-2935.

19 Turner HE, Harris AL, Melmed S \& Wass JA. Angiogenesis in endocrine tumors. Endocrine Reviews 200324 600-632.

20 Turner HE, Nagy Z, Sullivan N, Esiri MM \& Wass JA. Expression analysis of cyclins in pituitary adenomas and the normal pituitary gland. Clinical Endocrinology (Oxford) 200053 337-344.

21 Asa SL \& Ezzat S. The pathogenesis of pituitary tumours. Nature Reviews Cancer 20022 836-849.

22 Barlier A, Gunz G, Zamora AJ, Morange-Ramos I, FigarellaBranger D, Dufour H, Enjalbert A \& Jaquet P. Pronostic and therapeutic consequences of Gs alpha mutations in somatotroph adenomas. Journal of Clinical Endocrinology and Metabolism 1998 $831604-1610$.

23 Ezzat S, Zheng L, Zhu XF, Wu GE \& Asa SL. Targeted expression of a human pituitary tumor-derived isoform of FGF receptor-4 recapitulates pituitary tumorigenesis. Journal of Clinical Investigation $2002 \mathbf{1 0 9} 69-78$.

24 Qian ZR, Sano T, Asa SL, Yamada S, Horiguchi H, Tashiro T, Li CC, Hirokawa M, Kovacs K \& Ezzat S. Cytoplasmic expression of fibroblast growth factor receptor-4 in human pituitary adenomas: relation to tumor type, size, proliferation, and invasiveness. Journal of Clinical Endocrinology and Metabolism 200489 1904-1911.

25 Zhang X, Sun H, Danila DC, Johnson SR, Zhou Y, Swearingen B \& Klibanski A. Loss of expression of GADD45 gamma, a growth inhibitory gene, in human pituitary adenomas: implications for tumorigenesis. Journal of Clinical Endocrinology and Metabolism $2002871262-1267$.

26 Zhang X, Horwitz GA, Heaney AP, Nakashima M, Prezant TR, Bronstein MD \& Melmed S. Pituitary tumor transforming gene (PTTG) expression in pituitary adenomas. Journal of Clinical Endocrinology and Metabolism $1999 \mathbf{8 4} 761-767$.

27 Marx SJ \& Nieman LK. Aggressive pituitary tumors in MEN1: do they refute the two-hit model of tumorigenesis? Journal of Clinical Endocrinology and Metabolism 200287 453-456.

28 Verges B, Boureille F, Goudet P, Murat A, Beckers A, Sassolas G, Cougard P, Chambe B, Montvernay C \& Calender A. Pituitary disease in MEN type 1 (MEN1): data from the France-Belgium MEN1 multicenter study. Journal of Clinical Endocrinology and Metabolism 200287 457-465.

29 Verloes A, Stevenaert A, Teh BT, Petrossians P \& Beckers A. Familial acromegaly: case report and review of the literature. Pituitary $19991273-277$.

30 McCarthy MI, Noonan K, Wass JA \& Monson JP. Familial acromegaly: studies in three families. Clinical Endocrinology (Oxford) $199032719-728$.

31 Stevenaert A \& Beckers A. Presurgical octreotide: treatment in acromegaly. Metabolism $1996 \mathbf{4 5} 72-74$.

32 Newman CB, Melmed S, George A, Torigian D, Duhaney M, Snyder P, Young W, Klibanski A, Molitch ME, Gagel R, Sheeler L, Cook D, Malarkey W, Jackson I, Vance ML, Barkan A, Frohman L \& Kleinberg DL. Octreotide as primary therapy for acromegaly. Journal of Clinical Endocrinology and Metabolism $1998 \mathbf{8 3}$ 3034-3040.

33 Bevan JS, Atkin SL, Atkinson AB, Bouloux PM, Hanna F, Harris PE James RA, McConnell M, Roberts GA, Scanlon MF, Stewart PM, Teasdale E, Turner ME, Wass JAH \& Wardlaw JM. Primary medical therapy for acromegaly: an open, prospective, multicenter study of the effects of subcutaneous and intramuscular slowrelease octreotide on growth hormone, insulin-like growth factor-I, and tumor size. Journal of Clinical Endocrinology and Metabolism $2002874554-4563$.

34 Clemmons DR, Chihara K, Freda PU, Ho KK, Klibanski A, Melmed S, Shalet SM, Strasburger CJ, Trainer PJ \& Thorner MO. Optimizing control of acromegaly: integrating a growth hormone receptor antagonist into the treatment algorithm. Journal of Clinical Endocrinology and Metabolism $2003 \mathbf{8 8} 4759-4767$.

35 AACE Medical Guidelines for Clinical Practice. The diagnosis and treatment of acromegaly. Endocrine Practice 200410 213-225.

36 Freda PU. Somatostatin analogs in acromegaly. Journal of Clinical Endocrinology and Metabolism 200287 3013-3018.

37 Bevan JS. The anti-tumoral effects of somatostatin analog therapy in Acromegaly. Journal of Clinical Endocrinology and Metabolism $2005901856-1863$.

38 Giusti M, Ciccarelli E, Dallabonzana D, Delitala G, Faglia G, Liuzzi A, Gussoni G \& Disem GG. Clinical results of long-term slow-release lanreotide treatment of acromegaly. European Journal of Clinical Investigation 199727 277-284.

39 Suliman M, Jenkins R, Ross R, Powell T, Battersby R \& Cullen DR. Long-term treatment of acromegaly with the somatostatin 
analogue SR-lanreotide. Journal of Endocrinological Investigation $199922409-418$.

40 Tauber JP, Babin T, Tauber MT, Vigoni F, Bonafe A, Ducasse M, Harris AG \& Bayard F. Long term effects of continuous subcutaneous infusion of the somatostatin analog octreotide in the treatment of acromegaly. Journal of Clinical Endocrinology and Metabolism $198968917-924$.

41 Barakat S \& Melmed S. Reversible shrinkage of a growth hormone-secreting pituitary adenoma by a long-acting somatostatin analogue, octreotide. Archives of Internal Medicine 1989149 1443-1445

42 Arosio M, Macchelli S, Rossi CM, Casati G, Biella O \& Faglia G. Effects of treatment with octreotide in acromegalic patients-a multicenter Italian study. Italian Multicenter Octreotide Study Group. European Journal of Endocrinology 1995133 430-439.

43 Ezzat S, Snyder PJ, Young WF, Boyajy LD, Newman C, Klibanski A et al. Octreotide treatment of acromegaly. A randomized, multicenter study. Annals of Internal Medicine $1992117711-718$.

44 Flogstad AK, Halse J, Haldorsen T, Lancranjan I, Marbach P, Bruns C \& Jervell J. Sandostatin LAR in acromegalic patients: a dose-range study. Journal of Clinical Endocrinology and Metabolism $1995 \mathbf{8 0} 3601-3607$.

45 Stewart PM, Stewart SE, Clark PM \& Sheppard MC. Clinical and biochemical response following withdrawal of a long-acting, depot injection form of octreotide (Sandostatin-LAR). Clinical Endocrinology (Oxford) 199950 295-299.

46 Ezzat S, Horvath E, Harris AG \& Kovacs K. Morphological effects of octreotide on growth hormone-producing pituitary adenomas. Journal of Clinical Endocrinology and Metabolism $1994 \mathbf{7 9}$ $113-118$

47 Losa M, Ciccarelli E, Mortini P, Barzaghi R, Gaia D, Faccani G, Papotti M, Mangili F, Terreni MR, Camanni F \& Giovanelli M. Effects of octreotide treatment on the proliferation and apoptotic index of GH-secreting pituitary adenomas. Journal of Clinical Endocrinology and Metabolism 200186 5194-5200.

48 Trainer PJ, Drake WM, Katznelson L, Freda PU, Herman-Bonert V, van der Lely AJ, Dimaraki EV, Stewart PM, Friend KE, Vance ML, Besser GM \& Scarlett JA. Treatment of acromegaly with the growth hormone-receptor antagonist pegvisomant. New England Journal of Medicine $2000 \mathbf{3 4 2} 1171-1177$.

49 Ho KK. Place of pegvisomant in acromegaly. Lancet $20013 \mathbf{3 8}$ 1743-1744.

50 van der Lely AJ, Hutson RK, Trainer PJ, Besser GM, Barkan AL, Katznelson L, Klibanski A, Herman-Bonert V, Melmed S, Vance ML, Freda PU, Stewart PM, Friend KE, Clemmons DR, Johannsson G, Stavrou S, Cook DM, Phillips LS, Strasburger CJ, Hacker S, Zib KA, Davis RJ, Scarlett JA \& Thorner MO. Longterm treatment of acromegaly with pegvisomant, a growth hormone receptor antagonist. Lancet $20013 \mathbf{3 8} 1754-1759$.

51 van der Lely AJ, Muller A, Janssen JA, Davis RJ, Zib KA, Scarlett JA \& Lamberts SW. Control of tumor size and disease activity during cotreatment with octreotide and the growth hormone receptor antagonist pegvisomant in an acromegalic patient. Journal of Clinical Endocrinology and Metabolism $2001 \mathbf{8 6} 478-481$.

52 Thorner MO, Chait A, Aitken M, Benker G, Bloom SR, Mortimer CH, Sanders P, Mason AS \& Besser GM. Bromocriptine treatment of acromegaly. British Medical Journal $1975 \mathbf{1}$ 299-303.

53 Besser GM \& Wass JA. Medical management of acromegaly with bromocriptine. Effects of continuous treatment for over three years. Medical Journal of Australia 19782 31-33.

54 Jaffe CA \& Barkan AL. Treatment of acromegaly with dopamine agonists. Endocrinology and Metabolism Clinics of North America $199221713-735$.

55 Cozzi R, Attanasio R, Barausse M, Dallabonzana D, Orlandi P, Da Re N, Branca V, Oppizzi G \& Gelli D. Cabergoline in acromegaly: a renewed role for dopamine agonist treatment? European Journal of Endocrinology $1998139516-521$.

56 Abs R, Verhelst J, Maiter D, Van Acker K, Nobels F, Coolens JL, Mahler C \& Beckers A. Cabergoline in the treatment of acromegaly: a study in 64 patients. Journal of Clinical Endocrinology and Metabolism $1998 \mathbf{8 3} 374-378$.

57 Muratori M, Arosio M, Gambino G, Romano C, Biella O \& Faglia G. Use of cabergoline in the long-term treatment of hyperprolactinemic and acromegalic patients. Journal of Endocrinological Investigation $1997 \mathbf{2 0} 537-546$.

58 Oppizzi G, Liuzzi A, Chiodini P, Dallabonzana D, Spelta B, Silvestrini F, Borghi G \& Tonon C. Dopaminergic treatment of acromegaly: different effects on hormone secretion and tumor size. Journal of Clinical Endocrinology and Metabolism $1984 \mathbf{5 8}$ 988-992.

59 Eastman RC, Gorden P, Glatstein E \& Roth J. Radiation therapy of acromegaly. Endocrinology and Metabolism Clinics of North America $199221693-712$.

60 Barkan AL, Halasz I, Dornfeld KJ, Jaffe CA, Friberg RD, Chandler WF \& Sandler HM. Pituitary irradiation is ineffective in normalizing plasma insulin-like growth factor I in patients with acromegaly. Journal of Clinical Endocrinology and Metabolism $1997823187-3191$.

61 Melmed S, Casanueva FF, Cavagnini F, Chanson P, Frohman L, Grossman A, Ho K, Kleinberg D, Lamberts S, Laws E, Lombardi G, Vance ML, von Werder K, Wass J \& Giustina A. Guidelines for acromegaly management. Journal of Clinical Endocrinology and Metabolism 200287 4054-4058.

62 Izawa M, Hayashi M, Nakaya K, Satoh H, Ochiai T, Hori T \& Takakura K. Gamma knife radiosurgery for pituitary adenomas. Journal of Neurosurgery 200093 (Suppl 3) 19-22.

63 Cozzi R, Barausse M, Asnaghi D, Dallabonzana D, Lodrini S \& Attanasio R. Failure of radiotherapy in acromegaly. European Journal of Endocrinology $2001 \mathbf{1 4 5} 717-726$.

64 Lucas T, Astorga R \& Catala M. Preoperative lanreotide treatment for GH-secreting pituitary adenomas: effect on tumour volume and predictive factors of significant tumour shrinkage. Clinical Endocrinology (Oxford) $2003 \mathbf{5 8} 471-481$.

65 Abe T \& Ludecke DK. Effects of preoperative octreotide treatment on different subtypes of $90 \mathrm{GH}$-secreting pituitary adenomas and outcome in one surgical centre. European Journal of Endocrinology $2001145137-145$

Received 1 April 2005

Accepted 24 May 2005 